\title{
Social Network Attributes: The Implications of Working With Non-Native English Speakers for L2 Learners
}

\author{
Andarini Handayani \\ andarini.h@gmail.com \\ Universitas Negeri Semarang, Postgraduate Program
}

\begin{abstract}
In the maritime English context, one of the concerns is to improve and maintain the L2 English mastery of the seafarers to create a successful completion of work-related tasks in the ship. This paper aims to reveal to what extent living with non-native speakers in professional and personal domain enabling to contribute to the development or the detrimental effect of Indonesian seafarers' English mastery based on their language subjective experience and its unique implications. The social networks become the explanatory framework. A descriptive narrative design was employed using a questionnaire and interviews as the instruments. The result shows that the social network is indeed crucial and valuable for the English shift performance. Adverse effects are noticed due to the arbitrary speaking behavior produced by the other non-native speakers. Having adequate opportunity to practice English in the ship is also identified as a circumstance of an improved English mastery. Thus, the risk patterns noticed highlight the importance of communication training for L2 language proficiency.
\end{abstract}

Keywords: Seafarers, Social Network, Non-native English Speaker.

\section{Introduction}

The themes of plural worldviews and communicating across cultural identity and languages permeate the experience of social network in international setting. Increasingly, people are moving to pursuit of, for example, study, safety or work - as most seafarers do in the world. An inevitable consequence is that there will be many seafarers who are not a native English speaker coming from diverse background that should be working together in the ship. Thus, this condition demands the crews, who comes from different countries, to speak English. When a language develops a special role recognized by every country, it achieves a genuinely global status (1). As it is acknowledged, English is widely spoken by many seafarers for international communication. The seafarers may or may not be English native speakers and the events may or may not take place in English speaking country where English is spoken as a mother tongue. Graddol \& Meinhof claims that for every one native speaker, there are now three or four non-native speakers, a ratio that will increase as time goes by (2). As non-native group is increasing, there are going to be implications for future character of the language and the speakers itself.

In Maritime industry, non-native speaker - non-native speaker interaction and nonnative speaker - native speaker interaction are frequently occur, but as Kachru (3) highlights, the former is more common. In those situations, promoting or restricting the English by non- 
native seafarers is possible to happen as the effect of working in international setting. To know the implications of English mastery for Indonesian seafarers after working abroad with diverse background of people becomes the main issue in this study.

It is also noted that in maritime context, all standardized communications and safety procedures are written and announced in English. To communicate correctly and effectively, English is the only way out to deliver the message and meaning. Thus, English has a prominent role in the seafaring world. As a seafarer, it is an urge to learn English in order to avoid endangering the vessels. Having problem in understanding the documents and instructions can also put the crews in danger. Misunderstandings may create serious results, especially regarding to safety. Facing those facts, shipping companies had put a high standard of English mastery for seafarers.

In this regard, English language for seafarers has various influential roles. As it is postulated that language serves function to provide and structure meaning, to form relationships, to conceptualize ideas, to express needs and feelings and to shape our imagination $(4,5)$. The manner by which language is utilized to communicate is a reflection of social standards, which enables to manage individuals and communities. Not to able or only partially be able to speak another language may bring inadequacy at individual's ability to converse the meaning which leads to operate in restricted and childlike way.

A social network has been defined as informal social relationships contracted by an individual (6). A network is a group of people who know each other in various capacity. This group involves an anchor as the center who has specific link to different people from various domains of life. All of the domains are seen as the social network that being the connection between the anchor of the network and other persons. It is also possible, in a denser network, for the people within the domains to know each other, or an overlap between the domains. It means people from one domain are able to know people from another domain. Social network are chosen by any means significant in language development as its power in linguistic and cultural socialization.

Derakhshan \& Hasanabbasi proposed the notion that social interaction via social networks is an impetus for learners to make a communication (7). The research pinpoints the fact that the online social network can be used to improve students' language skills. This online social network help the L2 learners to expedite their language development. Social network relations are identified as the principal agent of language change. The present study is based on social networks approach (8-11) making it possible to investigate the L2 learners relationships with their community, such as workmates on board, as they are responsible for the non-native English learners enculturation and socialization into the communities.

\section{Methodology}

The present study adopted the method of the case study Yin (12 p13) that "investigates a phenomenon within its real-life context". Case study is suited to address "how" or "why" questions that concern the phenomenon (13). This study was a descriptive-narrative design using purposive sampling method. In purposive sampling, the researcher selected individuals and site that can best help to understand the phenomenon. The participant chosen has met the standard that provided useful information (14 p169) by virtue of knowledge or experience (15).

Self-report data have proved valuable to explore the individual differences of learners. Selfreport data can be obtained by means of written questionnaires such as used by Gardner et al. to 
measure learners' attitude an motivation (see (16)), and by means of oral interviews as used by Wenden to identify learners' beliefs about language learning (see (17))

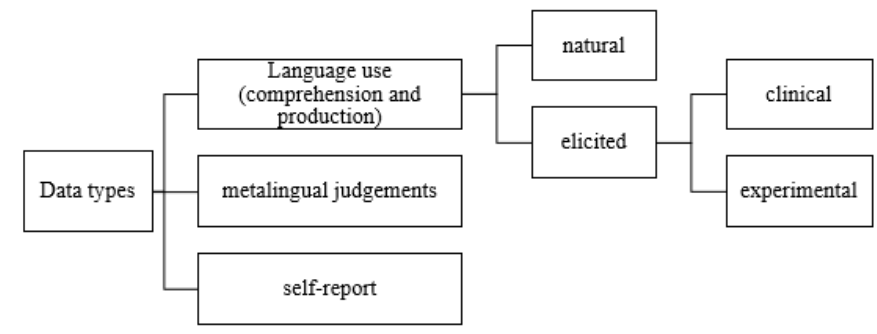

Fig. 1. The data type used in second language acquisition research

The data is provided from questionnaires and interview with two Indonesian seafarers. The participant in this study, Arya and Ibra (pseudonym; ethical approval was obtained from the participants before the study started), are an experienced seafarer in the BSM (Bernhard Schulte Shipmanagement) - a shipping company. Arya and Ibra were recruited as the seafarer after graduated from Merchant Marine Polytechnic Semarang and were among the few top students (based on GPA). Arya and Ibra obtained a S.ST. degree in Applied Science in which specifically engineering. While Arya had a great interest in Engineering, he also performed well in English proven by his success in becoming the vice of the English Club (inferred from the interview). Arya and Ibra were also recognized for an outstanding result of Marlins English test. This study took place after they worked in BSM for about two years. Based on their knowledge and experiences, both of them are met the requisites as the participant. Arya and Ibra's case could still cast light on how the social network, especially in international setting gives influence to their English speaking ability.

The study draws on data from the participants' by using open-ended questions on questionnaire. Creswell (18) postulated that the strength of this type of questioning is that it is enables to obtain useful information in order to support the theories and concept. To have deeper understanding of Arya and Ibra's personal reflection, semi-structured interviews were also held in a conversational manner through WhatsApp (for convenience consideration) and face-to-face informal meeting. The interviews were concerned with the learning experience and attempted to elicit the influence of working with non-native English speaking people. The interviews were both in English and Bahasa as it would be easier for Arya and Ibra to express their ideas and feelings in a candid manner.

Both questionnaires and interviews had provided rich data for further analysis. In social-network research, questionnaires and observation have become important elements in gaining data from subjects $(6,19,20)$, and some researchers primarily count on questionnaires (21). Adopting a social network perspective, this paper focuses on the personal experiences and its implication on L2 English learners' acquisition. 


\section{Finding and Discussion}

The analysis of the questionnaires and interviews revealed three main ideas, i.e. workplace as the social environment, obstacles and advantages experienced and language development. These notions could explain the implications to English mastery, whether it is going to be better or worst. The effects of each learning attitude are based on L2 learners' selfconceptions.

\subsection{Workplace as the Social Environment}

For an individuals, social environment and attitudes towards language become essential to define the social environment that may influence on individuals' language behaviors. In this paper, a more detailed focus on the individuals and their position within a net of social networks will be scrutinized. Arya and Ibra were accepted in BSM (Bernhard Schulte Shipmanagement) about six months after their graduation. BSM is a shipping company managing around 600 vessels with about 18.000 employees across the world through a network of 11 ship management, 24 crew service and 4 wholly-owned maritime training centers (www.bsshipmanagement.com). One of the BSM Crew Service Center is located in Indonesia alongside with other countries, such as China, Croatia, India, Ukraine etc. Thereby, becoming employee of BSM enables to meet and work with other people across the globe. From those crew services, most of the countries do not use English as their mother tongue. It makes that the employees should be able to meet the required standard of English proficiency since English is highly used as the means of the communication on board.

During the last voyage, Arya was placed in MSC Algeciras, in which the shipping lines were started from Singapore, India, Sri Lanka, Suez Channel, Turkey, Greece and Arabic countries. It took about six months in total after the contract signed until the crew changing. In each port, where the vessel boarded, it was quite often that the crews had an offshore activities in the city of each country. It also let them to explore the city and established personal relationship with other crews. The crews in MSC Algeciras, which in total is 22 persons, came from many countries, mostly from Myanmar, Russian, Ukrainian, Romanian and Indian. As it is known that people from those countries are also categorized as the L2 of English language or non-native English speakers.

Ibra also has an experience of working in oceangoing vessels (MOL Globe, Lady Margaux, Everhard Schulte, and Theresa Schulte) which have worldwide lines. Most of the crews, which came from countries such as India, Philippines, Russia, are not a native English speaker. Thereby, it can be said that Ibra had adequate exposure to non-native English speakers during his on board. Ibra liked most to get along with The Philippines since, for him, it was easy to converse with them. Having the same topic of interest during chit-chatting becomes the biggest reason to make it.

\subsection{Obstacles and Advantages Experienced}

In daily used in the ship, English is strongly promoted to communicate each other. However, regarding the diverse background of the crews, cultural and language boundaries possibly happened. In terms of culture, it was noticed the significant differences between European and Asian culture. As Arya said in his interview, "The culture which impacted me the most is the distinction between European culture and Asian culture." Western people, such as Russian, are likely to have a not-so-clean habit in regards to personal stuff compared to Asian 
people. Living in the same cabin may trigger a communication gap. However, since Arya realized this phenomena earlier by virtue of his abundant of experiences dealing with many people, he did not account this issue to his work performance. He realized that workmates are likely a family in the ship. Arya also established more tolerance regarding to religious way of thinking. People from Turkey, who are Muslim, do not mean implement the religious activity as Arya did. At first, he thought that as Muslim, they probably have the similar habit. Yet, later he realized that was not. It was also quite difficult for Arya to maintain his religious realm in the ship.

In terms of language boundaries, Arya had experienced anxiety and misunderstanding during his communication with non-native speakers but not much. From the interview, it can be inferred that Arya experienced anxiety and misunderstanding. "Only once, with electrician from Romanian who has better English than mine albeit the Romanian has lower position. Well, speaking with top people also make me nervous most of the time". Misunderstanding occurred because of different pronunciation. As Arya mentioned, for example, the word crow bar made the Arya confused when it was spoken by his Myanmar mate. It took a long time to understand what the speaker means. Describing the function and the shape of crow bar became the solution to find the meaning. This situation also was encountered by Ibra. He acknowledged that some crews do not understand about the order which create a misunderstanding. It happened because the other non-native speakers use their own dialect and accents. However, Ibra believes that correct pronunciation brings significant impact to the smoothness of communication even the crews have varied dialects and accents. Arya also emerged anxiety when he met his electrician who has better English than Arya. It is noted that electrician has lower position than Arya as the third engineer. This feeling successfully motivated Arya to learn English better due to his high self-esteem as having higher position. The different way of behave and speak among crews are admitted by Ibra who said that the position on the ship plays an important role in determining the crews' behaviors. More, crews from certain countries, such as Russia, Ukraine, Latvia, and Philippines have a very good English that also contributing to a good communication.

Further, age factor also influences how Arya communicate to the workmates. As an Indonesian, it is commanded that respecting older is compulsory for daily activities in every single condition. However, when he had subordinate who was older than him, it is challenging for him to give a directive speech. "Age doesn't take role in the job", said him during his interview. Relating to Arya's case, he experienced those factors, thus he produced a hesitated command at the first stage.

As those aforementioned notions of Arya encountered, he later realized what made him enjoy being worked with non-native speakers. In the questionnaire he mentioned that the thing that made him enjoy the workplace was not only the people, but mostly because of the shipping line. Thereby, the people with the social attributes does not give him significant impact on enjoying the job as seafarer. He mentioned that he liked going to Japan, "That's interesting". Although he had done the sea project in Japan, he still wants to get Japan shipping line. Having BSM's shipping line (not going to Japan) made him not fully enjoy his job.

\subsection{Language development}

As non-native speakers coming from many countries, they have different dialects and accents of English. Standardizing the pronunciation is partly successful during the English 
training. As a result, the non-native speaker of Arya's workmates speak as what they like which creates misunderstanding. Arya who was exposed to non-native speakers cannot get sufficient comprehensible input regarding his linguistics features. It may be worth-mentioning that comprehensible input is considered as a pivotal factors for L2 language development. Whilst Arya did not get this input, he produced arbitrary utterance as well. It means that an adequate language input is required for L2 to improve the English mastery. However, the descent English ability does not significantly influence the work performance. This report is strikingly different from Ibra's report which mentioning that his English is much improved after signing on board with non-native English speaker crewmates. For him, a great chance to practice English is in front of His eyes with no one spoke in their mother tongue. More, He realized that English becomes basic need to do communication on ship.

\section{Conclusion}

It can be inferred that the social network, especially non-native speakers, gives influence to the social and linguistics detrimental and salutary effect of Indonesian seafarers. Social attributes are also noticed during working with different background of people. The participants had emerged better understanding and tolerance towards people across the globe. Regarding linguistics development, after working with non-native speakers for several months, the participants encountered different outcome: a worst and a better English mastery. This inconsistent improvement of English leads to the suggestion of regular language training to maintain and recharge the English performance of the seafarer. The further study is expected to have broader sample of participants as well as a deeper analysis on how the utterance produced is analyzed. This initial finding leads to what specific linguistic features are changed or shifted.

\section{References}

[1] Crystal D. English as a Global Language. 2nd ed. Cambridge: Cambridge University Press; 2003.

[2] Graddol D, Meinhof UH. English in a changing world (AILA review 13). Guildford, UK: Biddles Ltd; 1999.

[3] Kachru BB. The alchemy of English: The spread, functions, and models of non-native Englishes. University of Illinois Press; 1986.

[4] Imberti P. Who resides behind the words? Exploring and understanding the language experience of the non-English-speaking immigrant. Fam Soc. 2007;88(1):67-73.

[5] Lyons J. Language, meaning, and context. 1981;

[6] Milroy L. Language and social networks. 1987;

[7] Derakhshan A, Hasanabbasi S. Social networks for language learning. Theory Pract Lang Stud. 2015;5(5):1090-5.

[8] Boissevain J, Mitchell JC. Network analysis: Studies in human interaction. Walter de 
Gruyter GmbH \& Co KG; 2018.

[9] Gunnarsson B-L. The writing process from a sociolinguistic viewpoint. Writ Commun. 1997;14(2):139-88.

[10] Milroy J. Linguistic variation and change: On the historical sociolinguistics of English. B. Blackwell; 1992.

[11] Milroy L, Li W. A social network approach to code-switching: The example of a bilingual community in Britain. 1995;

[12] Yin RK. Case study research: Design and methods (Vol. 5). 2003;

[13] Yazan B. Three approaches to case study methods in education: Yin, Merriam, and Stake. Qual Rep. 2015;20(2):134-52.

[14] Patton MQ. Qualitative evaluation and research methods. SAGE Publications, inc; 1990.

[15] Bernard HR. Research methods in anthropology: Qualitative and quantitative approaches. Rowman \& Littlefield; 2017.

[16] Gardner RC. Attitudes and motivation. Annu Rev Appl Linguist. 1988;9:135-48.

[17] Wenden A. Metacognition: An expanded view on the cognitive abilities of L2 learners. Lang Learn. 1987;37(4):573-97.

[18] Creswell. Educational research: planning, conducting, and evaluating quantitative and qualitative research. 4th ed. 2012.

[19] Gal S. Language shift: Social determinants of linguistic change in bilingual Austria. Academic Press New York; 1979.

[20] Tarone E. Sociolinguistics: A Brief Introduction. JSTOR; 1971.

[21] Allard R, Landry R. Ethnolinguistic vitality beliefs and language maintenance and loss. Maint loss Minor Lang. 1992;1:171-95. 